City University of New York (CUNY) CUNY Academic Works

2017

\title{
On Parsimony and Tautology in the Study of Acute Coronary Syndrome
}

\author{
Bianchi Renzo \\ Université de Neuchâtel \\ Irvin Sam Schonfeld \\ cUNY Graduate Center \\ Eric Laurent \\ Université Bourgogne - Franche-Comté
}

\section{How does access to this work benefit you? Let us know!}

More information about this work at: https://academicworks.cuny.edu/gc_pubs/453

Discover additional works at: https://academicworks.cuny.edu

This work is made publicly available by the City University of New York (CUNY).

Contact: AcademicWorks@cuny.edu 
Letter to the Editor

\title{
On parsimony and tautology in the study of acute coronary syndrome
}

\author{
Renzo Bianchi ${ }^{\mathrm{a}, *}$, Irvin Sam Schonfeld ${ }^{\mathrm{b}}$, Eric Laurent ${ }^{\mathrm{c}}$ \\ a University of Neuchâtel, Institute of Work and Organizational Psychology, Neuchâtel, NE, Switzerland \\ b The City College of the City University of New York, Department of Psychology, New York City, NY, USA \\ ' Bourgogne Franche-Comté University, Laboratory of Psychology (EA 3188), Besançon, France
}

\section{A R T I C L E I N F O}

\section{Article history:}

Received 10 February 2017

Accepted 17 February 2017

\section{Keywords:}

Acute coronary syndrome

Burnout

Depression

Exhaustion

Methodology

In a recent study, Zhang et al. [1] concluded that burnout was associated with poor physical function and low quality of life after acute coronary syndrome (ACS). In our estimation, the authors' study has at least two unnoticed, though major, methodological limitations.

First, the authors did not adjust for depressive symptoms in their statistical analyses. This is problematic because (a) burnout is known to overlap with depression [2,3]-a finding overlooked by the authors-and (b) depression has been associated with ACS [4]. With depressive symptoms unexamined, it is unclear whether burnout accounts for unique variance in physical function and quality of life.

Second, the authors used the "personal burnout" subscale of the Copenhagen Burnout Inventory (CBI) [5] to assess burnout, a questionable methodological choice. Indeed, many CBI items explicitly refer to somatic fatigue and fragility (e.g., "How often do you feel tired?"; "How often are you physically exhausted?"; "How often do you feel weak and susceptible to illness?") and are therefore likely to overlap with the dependent variable "physical function." Thus the authors risk drawing tautologic conclusions-e.g., tired, physically exhausted, and weak and susceptible-to-illness people (as indexed by the measure of burnout) present with poorer physical function.

The aforementioned limitations suggest that Zhang et al.'s [1] conclusions should be considered cautiously. The key issues of confounding factors and overlap between independent and dependent variables need to be more systematically considered in ACS research.

\section{Conflict of interest}

The authors report no relationships that could be construed as a conflict of interest.

\section{References}

[1] M. Zhang, Y. Shi, Y. Yang, L. Liu, J. Xiao, T. Guo, J. Li, Burnout is associated with poo recovery of physical performance and low quality of life in patients after their first episode of acute coronary syndrome: a hospital-based prospective cohort study, Int J. Cardiol. 227 (2017) 503-507.

[2] R. Bianchi, I.S. Schonfeld, E. Laurent, Physician burnout is better conceptualized as depression, Lancet. Eur. Psychiatry 389 (2017) 1398.

[3] R. Bianchi, I.S. Schonfeld, P. Vandel, E. Laurent, On the depressive nature of the "burnout syndrome": a clarification, Eur. Psychiatry 41 (2017) 109-110.

[4] J.C. Huffman, C.M. Celano, J.L. Januzzi, The relationship between depression, anxiety, and cardiovascular outcomes in patients with acute coronary syndromes, Neuropsychiatr. Dis. Treat. 6 (2010) 123-136.

[5] T.S. Kristensen, M. Borritz, E. Villadsen, K.B. Christensen, The Copenhagen burnout inventory: a new tool for the assessment of burnout, Work Stress. 19 (2005) 192-207.

\footnotetext{
* Corresponding author at: University of Neuchâtel, Institute of Work and Organizational Psychology, Émile-Argand 11, 2000 Neuchâtel, NE, Switzerland.

E-mail address: renzo.bianchi@unine.ch (R. Bianchi).
} 